\title{
A Microstructure Evolution Model for Intercritical Annealing of a Low-carbon Dual-phase Steel
}

\author{
Mykola KULAKOV, ${ }^{*}$ Warren J. POOLE and Matthias MILITZER \\ The Centre for Metallurgical Process Engineering, The University of British Columbia, 309-6350 Stores Road Vancouver, British \\ Columbia, V6T 1 Z4 Canada.
}

(Received on March 8, 2014; accepted on July 23, 2014)

\begin{abstract}
A model was developed to describe the microstructure evolution during intercritical annealing of a lowcarbon steel suitable for industrial production of DP600 grade dual-phase steel on a hot-dip galvanizing line. The microstructure evolution model consists of individual submodels for ferrite recrystallization, austenite formation and decomposition constructed using the Johnson-Mehl-Avrami-Kolmogorov approach and the additivity principle. The submodels for recrystallization and austenite formation are adopted from a previous study. The present paper provides a detailed analysis of the model development for the decomposition of intercritical austenite. The overall microstructure evolution model is validated using simulated industrial thermal paths for intercritical annealing. Model validation is expedited by in-situ measurements of the recrystallization completion temperature using laser ultrasonics and the intercritical austenite formation and decomposition using dilatometry.
\end{abstract}

KEY WORDS: dual-phase steels; intercritical annealing; microstructure evolution model; recrystallization; austenite formation; austenite decomposition.

\section{Introduction}

Dual phase (DP) steels with a ferrite-martensite microstructure were developed in the late 1970's. ${ }^{1}$ The strengthening effect in DP structures is achieved by the addition of hard martensite into the ferrite matrix. The associated inhomogeneous plastic deformation leads to high strain hardening rates and a good combination of strength and ductility. Initially hot-rolled DP steels remained a niche product for wheel discs and rims. Since the early 2000's cold-rolled and coated DP steels have been a material of choice for car makers and are now routinely used for producing a wide range of components in modern cars.

To produce the dual-phase structure in these materials, cold-rolled steels are typically intercritically annealed on a hot-dip galvanizing line. A sequence of metallurgical phenomena including recovery, recrystallization, austenite formation and austenite decomposition takes place in the course of annealing. After complete or partial recrystallization, followed by intercritical austenite formation, a mixture of ferrite and austenite exists before the onset of cooling, where austenite transforms partially back into ferrite. The mechanisms of ferrite formation are, however, different from those involving nucleation and growth when ferrite forms from a fully austenized microstructure. After intercritical annealing, the new ferrite forms from the pre-existing ferrite without nucleation through epitaxial growth, i.e. with the same crystallographic orientation. ${ }^{2-7)}$ Typically during

\footnotetext{
* Corresponding author: E-mail: nkulako@gmail.com

DOI: http://dx.doi.org/10.2355/isijinternational.54.2627
}

epitaxial ferrite growth upon cooling, there is insufficient time for alloying elements including carbon to redistribute completely, which leads to the existence of concentration gradients in austenite: Higher carbon concentrations are found near the ferrite-austenite interface and lower concentrations in the centre of austenite islands. ${ }^{8}$ Depending on chemical composition, at lower temperatures, e.g. during the time spent in the molten zinc bath and the subsequent equalizing, bainite may also form. ${ }^{9,10)}$ The remaining austenite transforms into martensite during the final cooling to room temperature. The enrichment of alloying elements in austenite near the ferrite-austenite interface was also reported to decelerate austenite transformation into bainite and martensite. ${ }^{8)}$ The final microstructure, therefore, despite the term "dual-phase", may contain, in addition to ferrite and martensite, bainite as well.

Microstructure and properties of intercritically annealed steels are sensitive to processing conditions. Therefore, microstructure evolution models are useful for process design, optimization and control. Recently, a number of advanced microstructure models for intercritical annealing have been proposed using meso-scale modelling approaches including cellular automata and phase field methods. ${ }^{1-13)}$ However, for the industrial environment, pragmatic models with less computational overhead are still of relevance, e.g. spreadsheet-type models and/or numerical approaches suitable for on-line models. Such models have been developed to describe recrystallization ${ }^{14-17)}$ and austenite formation. ${ }^{17-20)}$ Models describing decomposition of intercritical annealing have received less attention as compared to decomposition from a fully austenitic state. ${ }^{21-25)}$ Several attempts have been 
made to couple these separate models to describe the entire microstructure evolution during intercritical annealing. ${ }^{26-28)}$ For example, a phenomenological model describing microstructure evolution during intercritical annealing of a transformation-induced plasticity steel with hot-rolled ferrite-pearlite initial microstructure was developed; however, no recrystallization model was required. ${ }^{26)}$ Austenite formation was described using the Johnson-Mehl-Avrami-Kolmogorov (JMAK) model. Similarly, the JMAK model was used to describe the austenite-to-bainite transformation during low temperature isothermal annealing, whereas the potential formation of epitaxial ferrite was not considered in the model. A refined version of an intercritical annealing model was proposed later, which included also a mixed-mode transformation submodel to describe the growth of epitaxial ferrite. ${ }^{27)}$ The model was applicable to a wide range of lowcarbon steels with ferrite-pearlite initial microstructures. However, recrystallization of a cold-rolled structure prior to austenite formation remained unaccounted for in this model.

Experimental studies have shown, that different morphologies and distributions of ferrite and austenite in intercritically annealed samples can be achieved by heat treating different initial microstructures. ${ }^{17}$ The present paper builds on these results by considering austenite decomposition from three different 50 pct ferrite -50 pct austenite microstructures formed after recrystallization completion. An austenite decomposition model is proposed and combined with the recrystallization and austenite formation models from the previous study to formulate an overall microstructure evolution model for intercritical annealing.

\section{Material and Experimental Procedures}

Major alloying elements in the material employed in this study are listed in Table 1. Other elements including phosphor, sulfur and aluminum accounted only for 0.111 wt. pct. For the austenite decomposition studies, 50 pct cold-rolled sheets with three different initial microstructures, i.e. ferritepearlite, ferrite-bainite-pearlite and martensite were produced (for a detailed description of the heat-treatments and microstructure analysis, $\left.\operatorname{se}^{17)}\right)$. Samples with dimensions of $60 \times 10 \times 1.8 \mathrm{~mm}$ samples were machined from the ascold-rolled sheets with the rolling direction parallel to the longitudinal axis of the samples. All heat treatments were conducted using the Gleeble 3500 thermo-mechanical simulator (Dynamic Systems Inc., Poestenkill, NY) under a vacuum of $0.26 \mathrm{~Pa}$. Temperature was controlled through a K-type thermocouple spot-welded at the centre of each sample. A dilatometer was attached to the samples to monitor dimensional changes in the transverse direction in the course of heat treatments. Thermal paths for the austenite decomposition experiments imitated intercritical annealing on a hot-dip galvanizing line and involved heating at $1{ }^{\circ} \mathrm{C} / \mathrm{s}$, intercritical annealing at $770^{\circ} \mathrm{C}$, cooling at 3,10 or $30^{\circ} \mathrm{C} / \mathrm{s}$ and $180 \mathrm{~s}$ long holding at $465^{\circ} \mathrm{C}$, as schematically shown in

Table 1. Major alloying elements in the investigated steel (wt. pct).

\begin{tabular}{cccc}
\hline $\mathrm{C}$ & $\mathrm{Mn}$ & $\mathrm{Si}$ & $\mathrm{Cr}$ \\
\hline 0.105 & 1.858 & 0.157 & 0.340 \\
\hline
\end{tabular}

Fig. 1. The austenite formation and completion temperatures were $A_{e 1}=690^{\circ} \mathrm{C}$ and $A_{e 3}=812^{\circ} \mathrm{C}$, respectively, as calculated using Thermo-Calc assuming orthoequilibrium (FE-2000 database, Thermo-Calc Software, Stockholm, Sweden). Holding times in the intercritical region at $770^{\circ} \mathrm{C}$ were selected to achieve a 50 pct ferrite -50 pct austenite structure before cooling. Partially austenized samples were water-quenched to convert all intercritical austenite into martensite and analyze microstructures existing prior to cooling in detail. Volume fractions of ferrite and martensite were then measured using the point counting method (ASTM E652-11) on secondary electron micrographs after etching with 2 pct Nital for $\sim 5 \mathrm{~s}$. The volume fractions are reported as the average value obtained from the analysis of fifteen micrographs. The ferrite-martensite interface area per volume, $\rho_{\alpha / \gamma}$, was determined according to: ${ }^{29)}$

$$
\rho_{\alpha / \gamma}=2 \cdot P_{L}
$$

where $P_{L}$ is the number of intercepts between test lines and the ferrite-martensite interface. The test lines were oriented parallel to the rolling and normal directions; three micrographs were analyzed for each condition.

After helium-assisted cooling at $\sim 100^{\circ} \mathrm{C} / \mathrm{s}$ to room temperature (see Fig. 1), ferrite, bainite and martensite were present in the final microstructure. Their volume fractions were measured using the point counting method on fifteen micrographs. Austenite decomposition kinetics was determined using changes in the sample dimensions during cooling and $465^{\circ} \mathrm{C}$ holding: Linear portions of the dilation curve in the beginning and end of cooling were extrapolated to intermediate temperatures, and the dilation signal was analyzed using the lever rule (ASTM A1033-10) with austenite content changing between $\sim 50$ pct and martensite volume fraction in the final microstructure. Epitaxial ferrite content, i.e. ferrite formed during cooling, was estimated indirectly as the difference between intercritical austenite volume fraction, i.e. $\sim 50 \mathrm{pct}$, and the sum of martensite and bainite volume fractions at room temperature.

To validate the proposed microstructure model a number of typical industrial intercritical annealing paths were simulated. The Laser Ultrasonics for Metallurgy (LUMet) system attached to the Gleeble simulator was employed to monitor recrystallization. A detailed description of the experimental setup is provided elsewhere. ${ }^{30)}$ The velocity of ultrasonic waves in steels is sensitive to the crystallographic texture due to the elastic anisotropy of iron. ${ }^{31)}$ For the material studied

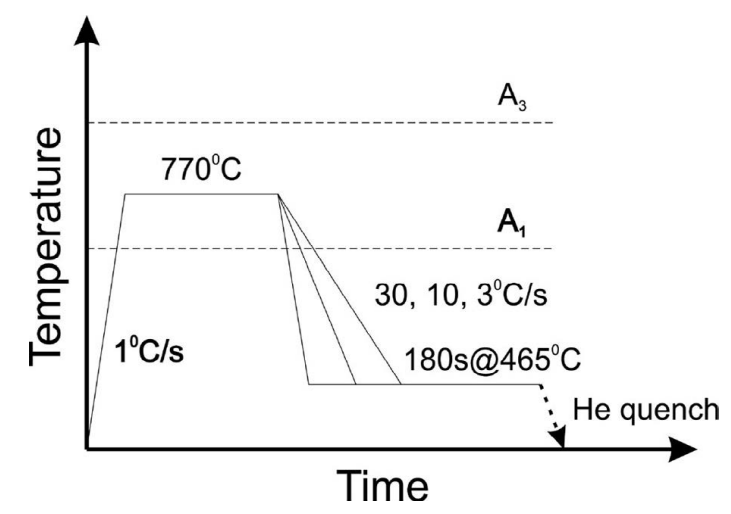

Fig. 1. Austenite decomposition experiments. 
here, the velocity of compressive ultrasonic waves increased significantly during the later stages of recrystallization accompanied by the changes in texture. ${ }^{30)}$ The recrystallization completion temperature was measured in-situ during simulations of the complete intercritical annealing cycles. In addition, kinetics of austenite formation and decomposition was tracked based on the lever rule analysis of the sample dilation.

\section{Experimental Results and Discussion}

\subsection{Results}

Figure 2 shows the three austenite-ferrite microstructures that were obtained during intercritical annealing at $770^{\circ} \mathrm{C}$ and provided the initial structures for the austenite decomposition experiments. The intercritical austenite formed from fully recrystallized structures since the heating rate of $1{ }^{\circ} \mathrm{C} / \mathrm{s}$ is sufficiently low to have recrystallization completed before the onset of austenite formation. ${ }^{17)}$ Austenite developed a necklace structure on the boundaries of recrystallized ferrite grains in the case of ferrite-bainite-pearlite and mar-
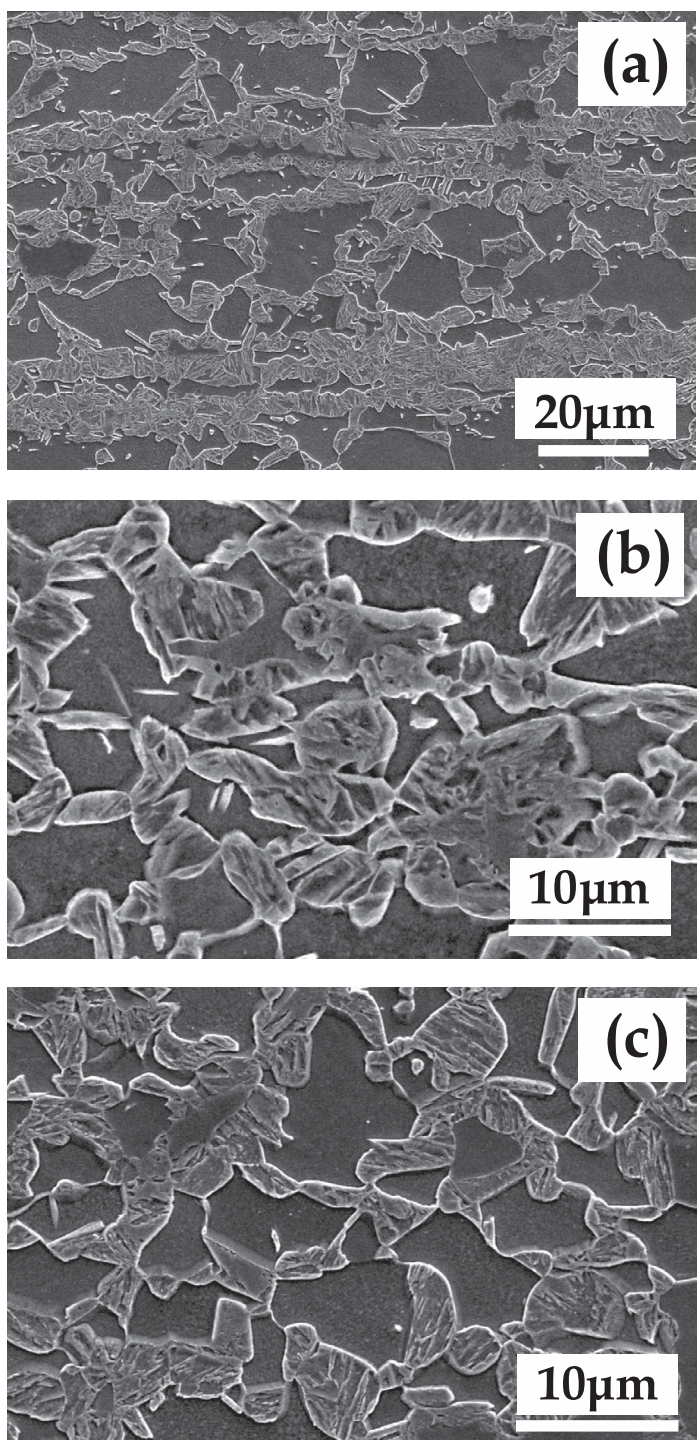

Fig. 2. 50 pct ferrite -50 pct austenite microstructures after intercritical annealing at $770^{\circ} \mathrm{C}$ of (a) ferrite-pearlite, (b) ferritebainite-pearlite and (c) martensite initial microstructures. (Note: Magnification is different in (a) from (b) and (c)) tensite initial microstructures; while for the coarser ferritepearlite initial microstructure, both the necklace and banded morphology of austenite were found. Results of the stereological analysis for the intercritical austenite microstructures are summarized in Table 2. In all three cases the microstructure consists of $\sim 45$ pct of austenite with the ferrite-austenite interface area per unit volume of $\sim 0.4 \cdot 10^{6} \mathrm{~m}^{-1}$.

The effect of cooling rate on austenite decomposition kinetics is illustrated in Fig. 3 for the example of intercritical austenite developed from the ferrite-pearlite initial microstructure (see Fig. 2(a)). During the cooling step, the transformation was, as expected, delayed to lower temperatures when the cooling rate was increased (see Fig. 3(a)). The austenite decomposition appears to have taken place in three stages, as can be inferred from the data for $3^{\circ} \mathrm{C} / \mathrm{s}$.

Table 2. Results of stereological analysis for three ferrite-austenite microstructures for austenite decomposition experiments.

\begin{tabular}{lccc}
\hline \multicolumn{1}{c}{$\begin{array}{c}\text { Initial } \\
\text { microstructure }\end{array}$} & $\begin{array}{c}\text { Austenite formation } \\
\text { conditions }\end{array}$ & $\begin{array}{c}\text { Austenite } \\
\text { content, } \\
\text { pct }\end{array}$ & $\begin{array}{c}\text { Ferrite-austenite } \\
\text { interface area per unit } \\
\text { volume, } \mathrm{m}^{2} / \mathrm{m}^{3} \cdot 10^{6}\end{array}$ \\
\hline $\begin{array}{l}\text { Ferrite-pearlite } \\
{ }^{\circ} \mathrm{C} / \mathrm{s}-770^{\circ} \mathrm{C}-1000 \mathrm{~s}\end{array}$ & $46 \pm 3$ & $0.35 \pm 0.10$ \\
$\begin{array}{l}\text { Ferrite-bainite- } \\
\text { pearlite }\end{array}$ & $1^{\circ} \mathrm{C} / \mathrm{s}-770^{\circ} \mathrm{C}-600 \mathrm{~s}$ & $47 \pm 3$ & $0.53 \pm 0.09$ \\
Martensite & $1^{\circ} \mathrm{C} / \mathrm{s}-770^{\circ} \mathrm{C}-600 \mathrm{~s}$ & $44 \pm 4$ & $0.41 \pm 0.08$ \\
\hline
\end{tabular}
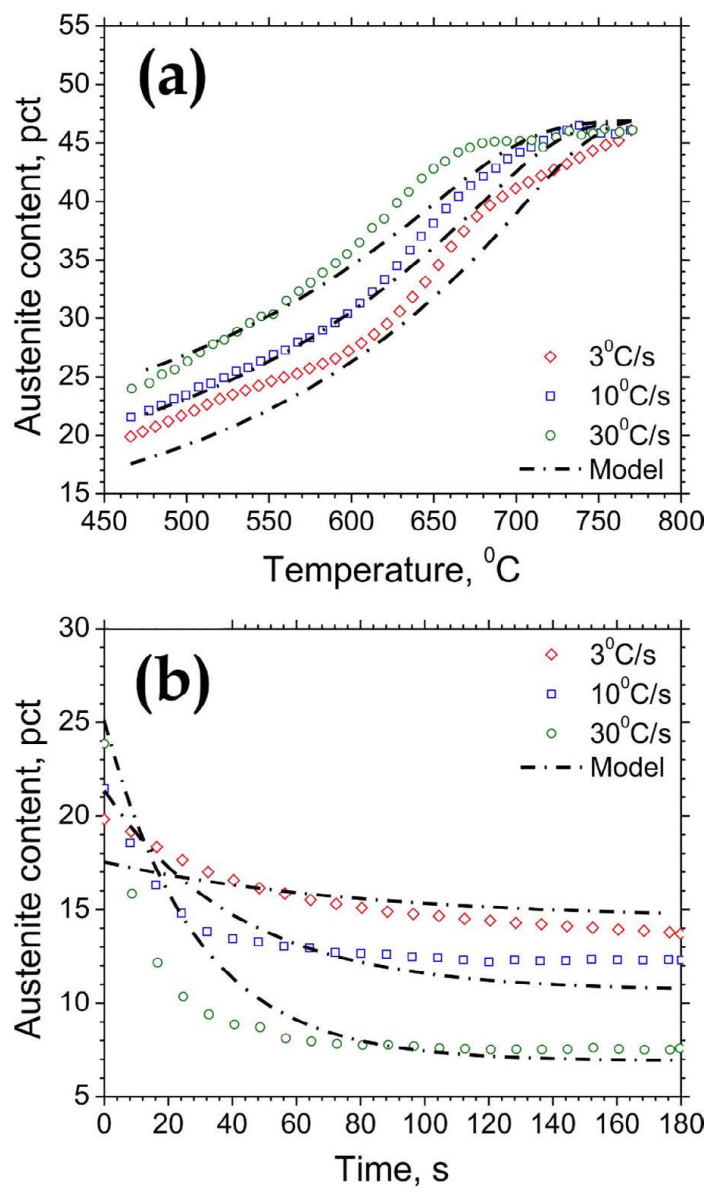

Fig. 3. Austenite decomposition rates after intercritical annealing of recrystallized ferrite-pearlite initial microstructure: (a) cooling from $770^{\circ} \mathrm{C}$ to $465^{\circ} \mathrm{C}$, (b) $180 \mathrm{~s}$ holding at $465^{\circ} \mathrm{C}$. (Symbols: experiments, lines: model) (Online version in color.) 
Here, the austenite decomposition rate was initially rather low until $\sim 670^{\circ} \mathrm{C}$ when the rate of transformation significantly increased before it slowed down again below about $600^{\circ} \mathrm{C}$. For cooling rates of $10^{\circ} \mathrm{C} / \mathrm{s}$ and higher, the initial transformation rates approached zero and the transformation stasis is observed. For example, at $30^{\circ} \mathrm{C} / \mathrm{s}$ austenite decomposition commenced at $\sim 670^{\circ} \mathrm{C}$, i.e. $100^{\circ} \mathrm{C}$ below the intercritical holding temperature. When the holding temperature of $465^{\circ} \mathrm{C}$ was reached, the remaining austenite content increased from 20 to 25 pct as cooling rate was raised from 3 to $30^{\circ} \mathrm{C} / \mathrm{s}$. During the subsequent holding at $465^{\circ} \mathrm{C}$, the remaining austenite was less stable after faster cooling (see Fig. 3(b)). The austenite decomposition process ceased after the first $\sim 60 \mathrm{~s}$ of the holding. The austenite content retained after the isothermal hold decreased from 14 to 6 pct for the slowest and fastest cooling rates, respectively.

The effect of initial microstructures on austenite decomposition kinetics is shown in Fig. 4 for $30^{\circ} \mathrm{C} / \mathrm{s}$ cooling. The transformation kinetics was essentially independent of the initial microstructure which is consistent with the similar intercritical austenite structures produced for all three cases, i.e. the same austenite content and similar levels of the ferrite-austenite interface area as shown in Table 2 . The different morphologies of austenite did not markedly affect the austenite decomposition kinetics.

Final microstructures after the complete intercritical
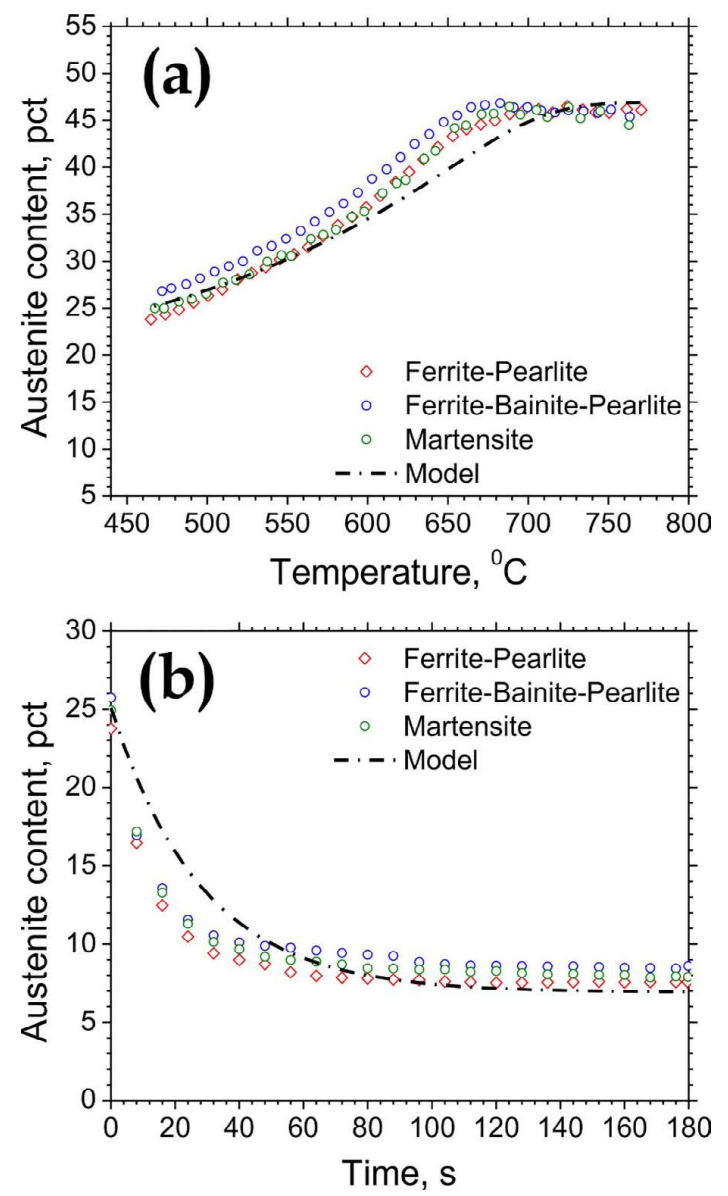

Fig. 4. Effect of microstructure after intercritical annealing on kinetics of austenite decomposition: (a) cooling from $770^{\circ} \mathrm{C}$ to $465^{\circ} \mathrm{C}$ at $30^{\circ} \mathrm{C} / \mathrm{s}$, (b) subsequent $465^{\circ} \mathrm{C}$ holding for $180 \mathrm{~s}$. (Symbols: experiments, lines: model) (Online version in color.) annealing cycle are shown in Fig. 5. Different microconstituents responded differently to the Nital etching. Ferrite was assigned to the dark homogeneous regions, areas containing white features (presumably cementites) were considered as bainite, while light grains corresponded to martensite. Ferrite can be further classified into two types: Ferrite that is not transformed into austenite during intercritical annealing and the one formed during cooling which will be referred to as intercritical and epitaxial ferrite, respectively. It was observed that bainite and martensite inherited the distribution and morphology of intercritical austenite, e.g. compare Figs. 2 and 5 . Bainite is nearly always surrounded by a rim of martensite, as indicated in the inserts of Fig. 5, suggesting that the interior of the austenite grains is a more suitable nucleation site for bainite than the vicinity of the ferrite-austenite interface.

Figure 6 shows the volume fraction of the three microstructure constituents resulting from the intercritical austenite decomposition. As already concluded from the dilation
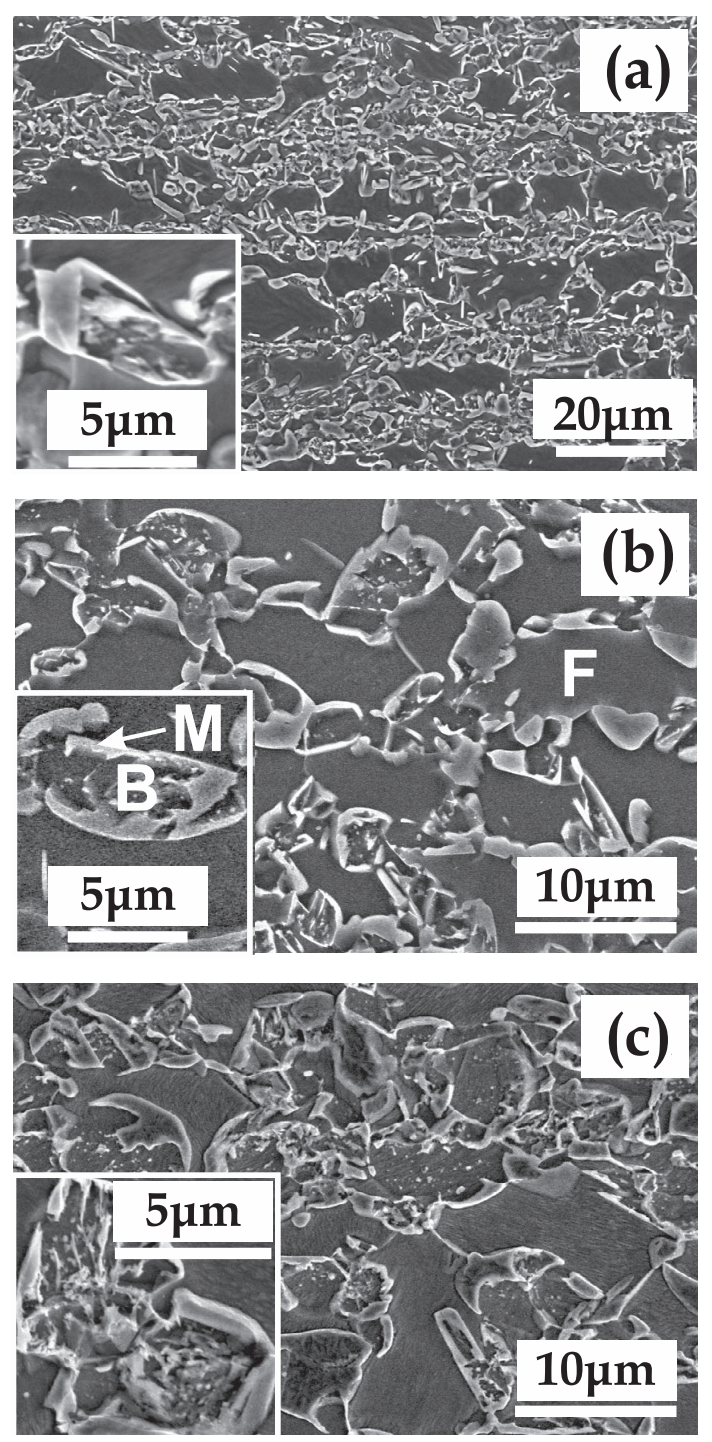

Fig. 5. Final microstructures after intercritical annealing at $770^{\circ} \mathrm{C}$ followed by cooling at $3^{\circ} \mathrm{C} / \mathrm{s}$ and $465^{\circ} \mathrm{C}$ hold for $180 \mathrm{~s}$ for (a) ferrite-pearlite, (b) ferrite-bainite-pearlite and (c) martensite initial microstructures. (Note: Magnification is different in (a) from (b) and (c); F - ferrite, B - bainite, $\mathrm{M}$ martensite) 
data, the martensite content decreases with cooling rate from $\sim 15$ to under 10 pct with some minor variations between the three cases. The combined content of bainite and martensite is relatively independent of cooling rate $\sim 30$ pct and the epitaxial ferrite fraction is also in a first approximation constant. In detail, there are some minor differences between the three different initial microstructures. The epitaxial ferrite content is approximately 20 pct for the ferrite-pearlite case (Fig. 6(a)), 10 pct for ferrite-pearlite bainite (Fig. 6(b)) and 15 pct for martensite (Fig. 6(c)). However, considering that the accuracy of measuring ferrite and bainite content is \pm 5 pct, it is reasonable to suggest that that for the investigated range of conditions independent of cooling rate and initial microstructure $\sim 15$ pct of epitaxial ferrite forms out of $\sim 45$ pct of intercritical austenite. Assuming that only one austenite decomposition product forms at a

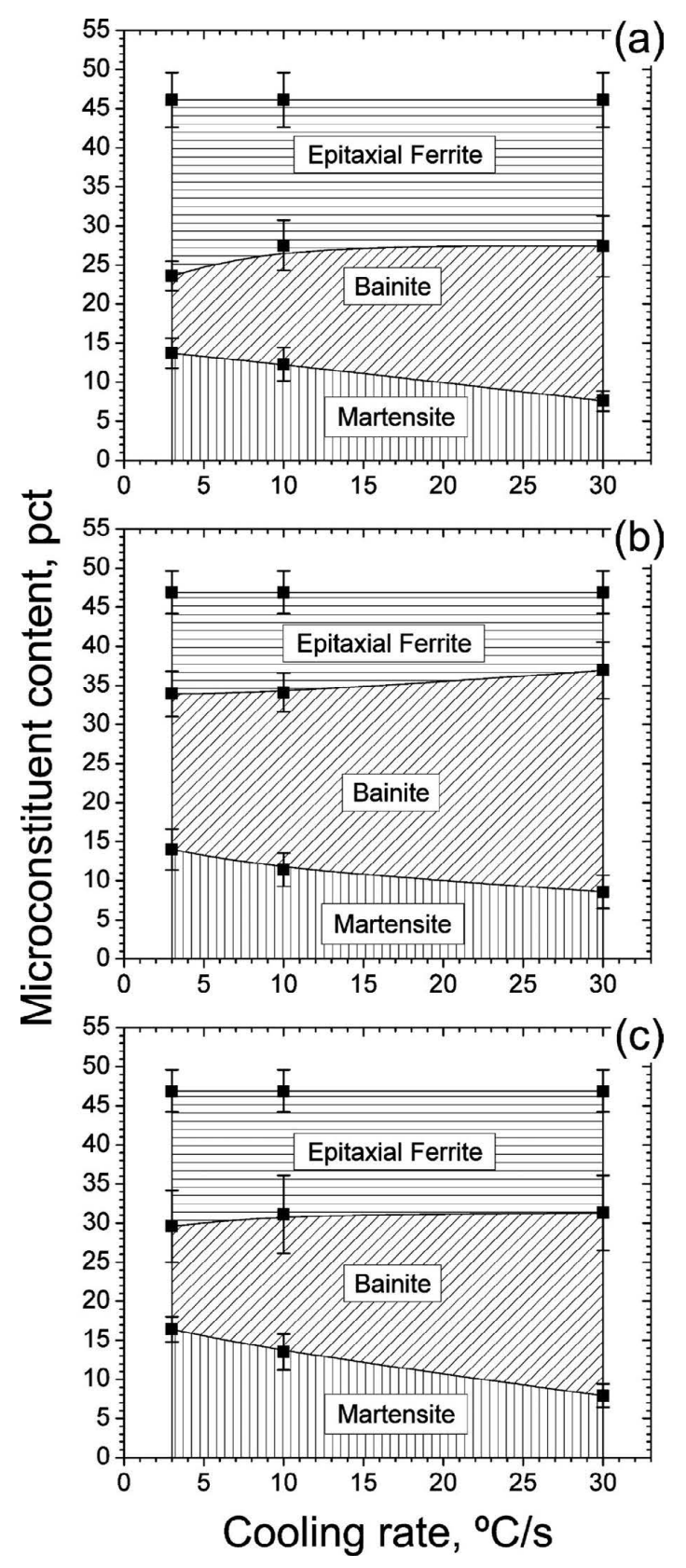

Fig. 6. Analysis of final microstructures after decomposition of intercritical austenite for (a) ferrite-pearlite, (b) ferritebainite-pearlite and (c) martensite initial microstructures. time, i.e. first epitaxial ferrite, then bainite and finally martensite; for all studied cases bainite formation is considered to start when austenite content reaches $\sim 30$ pct, i.e. the cumulative fraction of bainite and martensite in the final microstructure.

\subsection{Discussion}

These observations for the austenite decomposition and resulting microstructures can be rationalized as follows. The three transformation stages shown in Fig. 3(a) can be attributed to the formation of epitaxial ferrite in the first two stages and bainite in the third stage below $600^{\circ} \mathrm{C}$. The austenite content at the onset of the bainite formation concluded from the dilation data is remarkably consistent with the microstructure analysis with only a slight increase with cooling rate from 24 to 28 pct (see Figs. 3(a) and 6(a)). In the beginning of cooling, the austenite content decreases either very slowly or remains unchanged depending on cooling rate. For faster cooling, an undercooling below $770^{\circ} \mathrm{C}$ is necessary to initiate the austenite-to-ferrite transformation. The magnitude of the required undercooling increases with cooling rate. This temperature range is referred to as a stagnant stage in the literature. ${ }^{7,32,33)}$ The ferrite-austenite interface has to pass the manganese-rich region formed during prior austenite growth involving manganese partitioning. Manganese is an austenite stabilizer and the austenite near the interface is more stable than that with the nominal composition further away from the interface. As a result, the formation of epitaxial ferrite is initially inhibited but occurs readily for sufficiently high undercooling. As cooling rate increases, the transformation shifts to lower temperatures and the redistribution of carbon through austenite is less pronounced.

To analyze the carbon redistribution in more detail, its diffusion distance in austenite is considered first for the isothermal part of the intercritical anneals:

$$
L_{C}^{\gamma}=\sqrt{D_{C}^{\gamma} \cdot t}
$$

where $D_{C}^{\gamma}$ is the diffusion coefficient of carbon in austenite. ${ }^{34)}$ Even for the shortest intercritical annealing time of $t=600 \mathrm{~s}$ at $770^{\circ} \mathrm{C}$ employed to produce one of the three intercritical microstructures, the carbon diffusion distance in austenite, $L_{C}^{\gamma}$, of $23 \mu \mathrm{m}$ is considerably larger than the half width of the austenite grains shown in Fig. 2. Therefore, a uniform carbon concentration is established before cooling, as schematically shown in Fig. 7(a).

During the epitaxial growth of ferrite, carbon is rejected into austenite; a gradient in carbon concentration is thus created, Fig. 7(b). The carbon enrichment in the vicinity of the ferrite-austenite interface was recently shown to retard further austenite decomposition into bainite. ${ }^{8)}$ The observation of the martensite rims around bainite (recall Fig. 5) also suggests that the outer regions of austenite are more stable than the interior. The width of the carbon enrichment, in a first approximation, is equal to the diffusion distance of carbon in austenite during cooling:

$$
L_{C}^{\gamma}=\sqrt{\left(D_{C}^{\gamma}\right)_{a v} \cdot \frac{T_{2}-T_{1}}{q}}
$$

where $q$ is cooling rate and $\left(D_{C}^{\gamma}\right)_{a v}$ is the average diffusion coefficient of carbon in austenite between the cooling start and stop temperatures, $T_{1}$ and $T_{2}$, respectively, i.e. $\left(D_{C}^{\gamma}\right)_{a v}=$ 
(a)

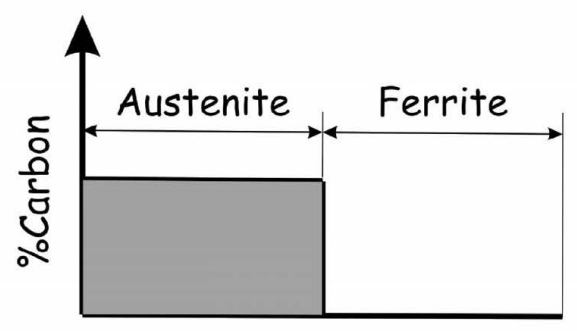

(b)

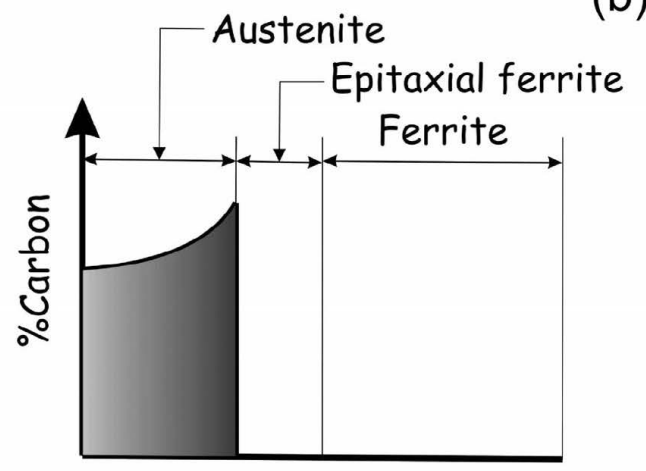

(c)

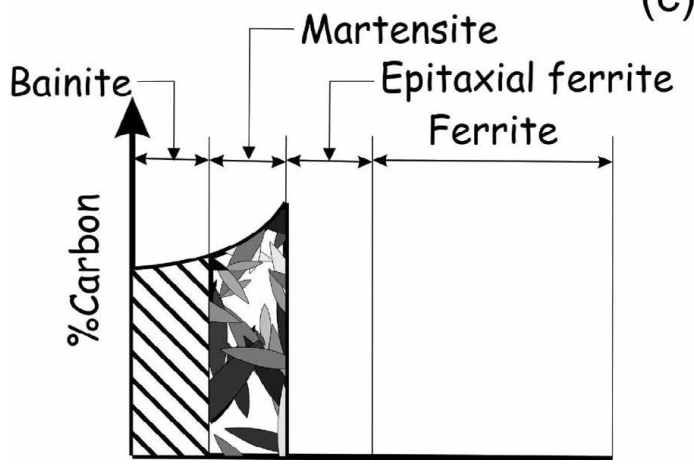

Fig. 7. Schematics of carbon redistribution leading to formation of martensite rim around bainite: (a) after holding at intercritical temperature, (b) after cooling to bainite start temperature, (c) at room temperature.

$\int_{T_{1}}^{T_{2}} D_{C}^{\gamma} \cdot d T / \int_{T_{1}}^{T_{2}} d T$. In the present case the carbon diffusion distance decreases from $\sim 4$ to $1 \mu \mathrm{m}$ when cooling rate is raised from 3 to $30^{\circ} \mathrm{C} / \mathrm{s}$. Further, bainite forms in the interior of the austenite particles as soon as conditions necessary for the bainite formation are met as schematically shown in Fig. 7(c). The austenite-to-bainite transformation in the centre region is promoted for higher cooling rates: The degree of the carbon enrichment is reduced and more bainite forms during the $465^{\circ} \mathrm{C}$ isothermal holding with an increase in the transformation rate (see Fig. 3(b)). During cooling to room temperature, any remaining austenite is transformed into martensite surrounding bainite.

\section{Modelling}

\subsection{Model Development}

Individual submodels accounting for different physical processes during intercritical annealing were first developed and then coupled to describe the complete microstructure evolution. The submodels are based on the JMAK equa- tion: ${ }^{35-37)}$

$$
f=1-\exp \left(-b \cdot t^{n}\right)
$$

where $f$ is the fraction transformed (or recrystallized), $b$ is a temperature-dependent rate parameter, and $n$ is the exponential factor.

Transformation kinetics during non-isothermal treatments can be described using the JMAK equation in its differential form and the additivity principle ${ }^{38,39)}$ provided $n$ is a constant:

$$
\frac{d f}{d t}=\left\{n \cdot(1-X) \cdot \ln \left(\frac{1}{1-X}\right)^{n-1 / n}\right\} \cdot b^{1 / n}
$$

Submodels describing the evolution of recrystallized volume fraction, $f_{R E X}$, were developed and validated previously. ${ }^{17}$ The rate of recrystallization was found to depend on the initial microstructure: Ferrite-pearlite shows slower recrystallization rates than ferrite-bainite-pearlite or martensite.

Models describing austenite formation for all three initial microstructures after recrystallization was completed were also previously developed. ${ }^{17}$ However, the interaction between recrystallization and austenite formation was not accounted for during rapid heating to the intercritical temperature region. Originally, separate austenite formation models were developed for each of the initial microstructures annealed using a wide range of heating rates and intercritical hold times. ${ }^{17)}$ Focusing here on relatively slow heating rates (up to $10^{\circ} \mathrm{C} / \mathrm{s}$ ) and long intercritical hold times (40-150 s), which are relevant to most scenarios for the industrial processing of dual-phase steels on a hot-dip galvanizing line, a single austenite formation model is proposed here for all three initial microstructures. The governing equations and model parameters from the previous work are summarized in Table 3. The actual austenite volume fraction, $f_{\gamma}$, is normalized by the ortho-equilibrium austenite content, $f_{\gamma}^{e q}$, within the intercritical region, i.e. between $A_{e 1}=690^{\circ} \mathrm{C}$ and $A_{e 3}=812^{\circ} \mathrm{C}$. The effect of heating rate, $p$, on the austenite formation start temperature, $A_{c 1}$ (in ${ }^{\circ} \mathrm{C}$ ), (when $f_{\gamma} / f_{\gamma}^{e q}=$ 0.05 ) is described empirically using a power function.

A two-stage austenite decomposition model is proposed here for the cooling stage and isothermal hold. Ferrite and bainite transformations are assumed to take place sequentially. For simplicity, the onset of bainite formation is taken to occur when the remaining austenite content reaches 30 pct (see Table 3). As such, the amount of bainite formed during cooling falls into the range of $\sim 5-10$ pct, as shown in Fig. 3(a), i.e. it is comparable to the measurement accuracy of the overall bainite content. Ferrite is thus the dominant austenite decomposition product during cooling. Even though the continuous cooling transformation occurs in three stages, it can, in a first approximation, be described with one set of JMAK parameters, i.e. both ferrite and bainite formation during cooling are described using the same model. The JMAK approach is then here of purely empirical nature. Since a mixture of ferrite and austenite exists at the beginning of cooling, the initial ferrite volume fraction is taken as $\left(1-f_{\gamma}\right)$. Unlike the austenite formation submodel, the austenite content is not normalized since the austeniteto-ferrite transformation takes place outside of the intercritical temperature range. The exponent $n$ of $\sim 1$ was typically 
Table 3. Recrystallization and austenite formation submodels.

\begin{tabular}{|c|c|}
\hline $\begin{array}{l}\text { Metallurgical } \\
\text { phenomenon }\end{array}$ & Equations and parameters \\
\hline \multirow{5}{*}{ Recrystallization ${ }^{17)}$} & $\frac{d f_{R E X}}{d t}=\left\{n \cdot\left(1-f_{R E X}\right) \cdot \ln \left(\frac{1}{1-X}\right)^{n-1 / n}\right\} \cdot b^{1 / n}$ \\
\hline & $b=b_{0} \cdot \exp (-Q / R \cdot T)$ \\
\hline & Ferrite-pearlite: $n=1.7 b_{0}=1.1 \cdot 10^{29} \mathrm{~s}^{-1.7} Q=581 \mathrm{~kJ} / \mathrm{mol}$ \\
\hline & Ferrite-bainite-pearlite: $n=1.4 b_{0}=2.3 \cdot 10^{27} \mathrm{~s}^{-1.4} Q=531 \mathrm{~kJ} / \mathrm{mol}$ \\
\hline & Martensite: $n=2.5 b_{0}=1.3 \cdot 10^{52} \mathrm{~s}^{-2.5} Q=1011 \mathrm{~kJ} / \mathrm{mol}$ \\
\hline \multirow{4}{*}{$\begin{array}{l}\text { Austenite formation } \\
\text { (after recrystallization } \\
\text { completion) }\end{array}$} & $\begin{array}{c}A_{c 1}=735 \cdot p^{0.012}\left(\text { when } f_{\gamma} / f_{\gamma}^{e q}=0.05\right)\left(T \text { in }{ }^{\circ} \mathrm{C}\right) \\
f^{e q}=25.78-0.07405 \cdot T+5.36 \cdot 10^{-5} \cdot T^{2}\left(\text { for } T=690 \text { to } 812^{\circ} \mathrm{C}\right)\end{array}$ \\
\hline & $\frac{d\left(f_{\gamma} / f_{\gamma}^{e q}\right)}{d t}=\left\{n \cdot\left(1-f_{\gamma} / f_{\gamma}^{e q}\right) \cdot \ln \left(\frac{1}{1-f_{\gamma} / f_{\gamma}^{e q}}\right)^{n-1 / n}\right\} \cdot b^{1 / n}$ \\
\hline & $b=b_{0} \cdot \exp (-Q / R \cdot T)$ \\
\hline & $n=0.4 b_{0}=3.6 \cdot 10^{18} \mathrm{~s}^{-0.4} Q=386 \mathrm{~kJ} / \mathrm{mol}$ \\
\hline \multirow{3}{*}{$\begin{array}{c}\text { Formation of } \\
\text { epitaxial ferrite and } \\
\text { bainite during cooling }\end{array}$} & $\frac{d f_{\alpha}}{d t}=\left\{n \cdot\left(1-f_{\alpha}\right) \cdot \ln \left(\frac{1}{1-f_{\alpha}}\right)^{n-1 / n}\right\} \cdot b^{1 / n}$ \\
\hline & $n=0.1 b=0.82+0.003 \cdot T-0.44 \cdot 10^{-5} \cdot T^{2}\left(T\right.$ in $\left.{ }^{\circ} \mathrm{C}\right)$ \\
\hline & Bainite starts to form when $f_{\gamma}=0.3$ \\
\hline \multirow{4}{*}{$\begin{array}{l}\text { Bainite formation } \\
\text { during } 465^{\circ} \mathrm{C} \\
\text { holding }\end{array}$} & $f_{B} / f_{B}^{\max }=1-\exp \left(-b \cdot t^{n}\right)$ \\
\hline & $n=1$ \\
\hline & $b=0.3 \cdot f_{\gamma}(t=0)-0.04$ \\
\hline & $f_{B}^{\max }=2 \cdot f_{\gamma}(t=0)-0.32$ \\
\hline
\end{tabular}

reported in the previously developed models employing the JMAK equation for ferrite formation from a fully austenitized state, see e.g. ${ }^{21,23)}$ However, in the present model for the ferrite formation from intercritical austenite, $n=0.1$ (see Table 3) is needed to describe the continuous cooling transformation which includes the stagnant stage in the beginning of cooling. Temperature dependence of the parameter $b$ is described using a second order polynomial rather than the Arrhenius relationship to capture the opposing effects of decreasing temperature on diffusion rates and driving pressure for austenite decomposition.

The austenite-to-bainite transformation during isothermal holding (here at $465^{\circ} \mathrm{C}$ ) is described with a separate JMAK model (see Table 3). Bainite fraction, $f_{B}$, is normalized over the maximum amount of bainite that can form during the holding, $f_{B}^{\max }$. The value of $f_{B}^{\max }$ is proportional to the volume fraction of austenite at the beginning of the isothermal hold, $f_{\gamma}(t=0)$, in accordance with the experimental observations. Any remaining austenite at the end of the $465^{\circ} \mathrm{C}$ hold is assumed to transform fully into martensite during the final cooling to room temperature. Figures 3 and 4 show examples of the quality of the austenite decomposition model fit to the experimental data. The model underestimates the duration of the stagnant stage and, therefore, predicts lower austenite volume fraction in the beginning of cooling; but by the end of the $465^{\circ} \mathrm{C}$ holding, the model output is in a good agreement with the measured austenite content.

Having developed submodels for recrystallization, aus- tenite formation and decomposition, a flowchart for the integrated microstructure evolution is shown in Fig. 8. The model is semi-empirical in nature and represents a pragmatic approach to the problem of the microstructure evolution during intercritical annealing. Initial microstructure and thermal path for intercritical annealing are the model inputs. Then, the recrystallization completion temperature predicted by the model is first compared to the austenite formation temperature. If recrystallization is completed before austenite forms, the model proceeds to the next segment. If recrystallization and austenization overlap, starting microstructure for austenite formation becomes a function of the degree of recrystallization completion. This complex process is not accounted for in the present model. Therefore, the model is limited to lower heating rates which are typical for hot-dip galvanizing lines although not necessarily for recently constructed continuous annealing lines where heating rates can approach $50^{\circ} \mathrm{C} / \mathrm{s}$. Austenite content prior to cooling predicted by the austenite formation model is used as an input for the austenite decomposition model. The formation of epitaxial ferrite and bainite during cooling and holding in the molten zinc bath at $465^{\circ} \mathrm{C}$ is described by the austenite decomposition model. The model is restricted to the $465^{\circ} \mathrm{C}$ holding temperature representative of the industrial processing route, as zinc baths typically operate in a narrow temperature range between 455 and $470^{\circ} \mathrm{C}$. Any remaining austenite at the end of the isothermal holding at $465^{\circ} \mathrm{C}$ is assumed to transform fully into martensite. Volume frac- 


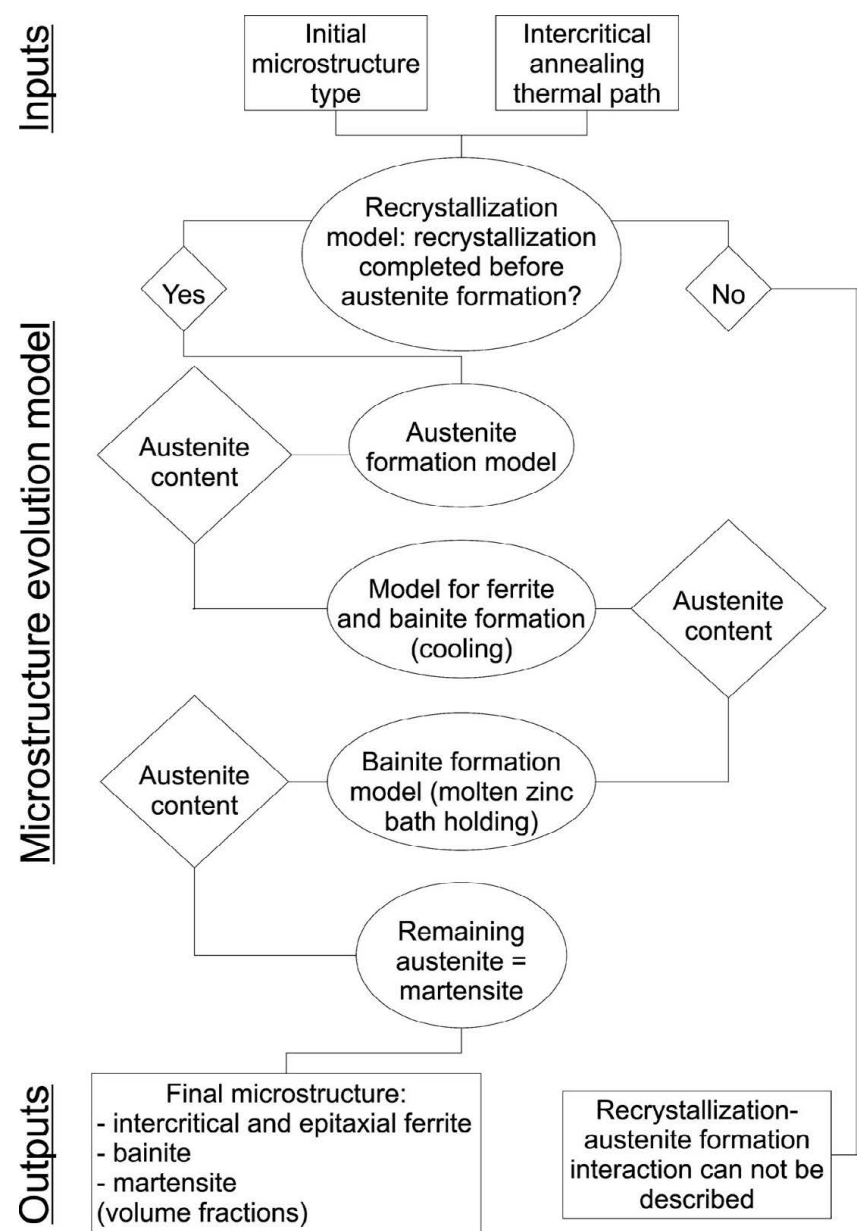

Fig. 8. Flow chart for integrated microstructure evolution model.

tions of intercritical and epitaxial ferrite, bainite and martensite are the model outputs.

The microstructure evolution model was implemented in a standalone application IntAnn (for Intercritical Annealing). The software was developed using Microsoft Visual Basic 2010 Express. For a non-isothermal thermal path, numerical integration was conducted with a $0.001 \mathrm{~s}$ time step; based on the sensitivity analysis further refinement of the time increment did not affect results of the calculations.

\subsection{Model Application}

The integrated microstructure evolution model has been validated with laboratory simulations of industrial intercritical annealing cycles typically employed for the investigated DP600 steel. The effect of the initial microstructure on the microstructure evolution has been evaluated for the processing route shown in Fig. 9(a) (total annealing time $\sim 380 \mathrm{~s}$; annealing time refers to the duration of the complete intercritical annealing cycle). The measured and predicted temperatures for recrystallization completion agree within $13^{\circ} \mathrm{C}$ or less, Table 4. The recrystallization models were developed based on stereological measurements of the recrystallization progress on individual micrographs taken at different through-thickness positions but still covering only a small fraction of the sample cross-sections. Laser ultrasonics, on the other hand, is a bulk measurement technique that samples material through the entire thickness but does not provide a direct measurement of recrystallized fraction per se.

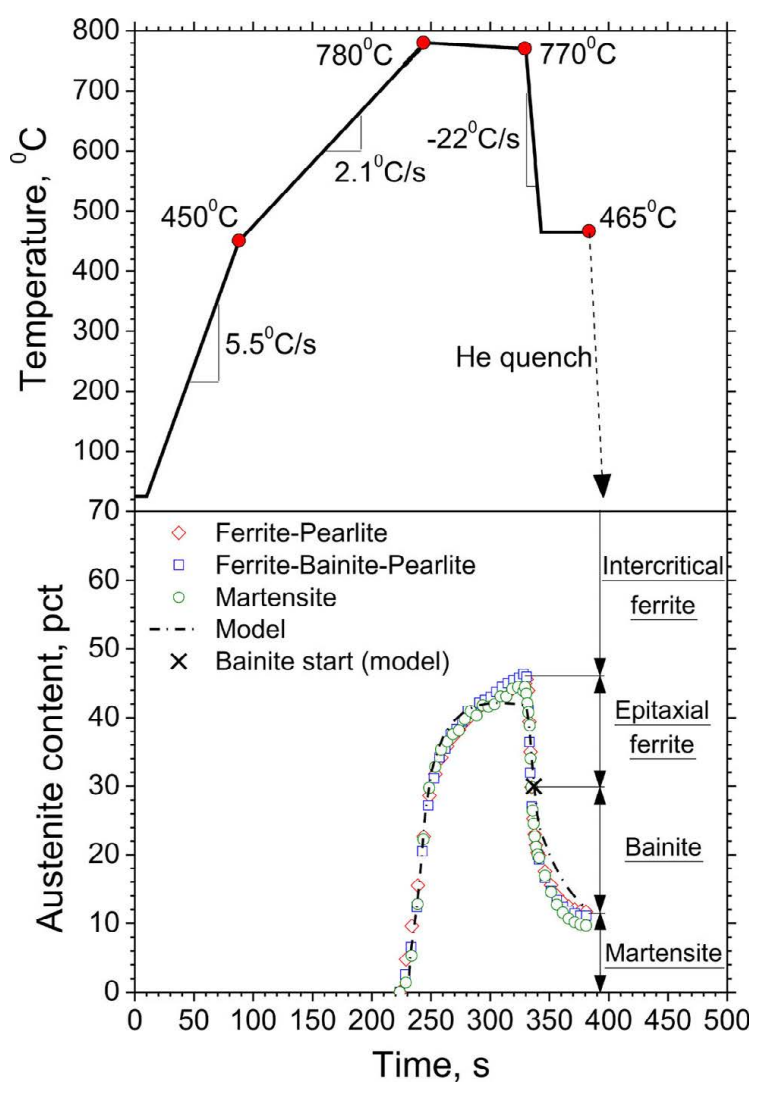

Fig. 9. Industrial intercritical annealing cycle and corresponding changes in austenite content for different initial microstructures. (Symbols: experiments, lines: model) (Online version in color.)

Table 4. Temperatures for recrystallization completion and austenite formation during laboratory simulations of industrial intercritical annealing of different initial microstructures.

\begin{tabular}{cccc}
\hline \multirow{2}{*}{$\begin{array}{c}\text { Initial } \\
\text { microstructure }\end{array}$} & $\begin{array}{c}\text { Recrystallization completion } \\
\text { temperature, }{ }^{\circ} \mathrm{C}\end{array}$ & $\begin{array}{c}\text { Austenite formation } \\
\text { temperature }(5 \mathrm{pct}- \\
\text { experiment), }{ }^{\circ} \mathrm{C}\end{array}$ \\
\cline { 2 - 3 } & Laser ultrasonics & Model $(99 \mathrm{pct})$ & 756 \\
\hline $\begin{array}{c}\text { Ferrite-pearlite } \\
\begin{array}{c}\text { Ferrite-bainite- } \\
\text { pearlite } \\
\text { Martensite }\end{array}\end{array}$ & 726 & 733 & 750 \\
\hline
\end{tabular}

The observed variations of ultrasound velocity are related to texture changes that are associated with recrystallization. Recrystallization stages that may have little or no texture variation cannot be observed with this technique. As a result, small discrepancies may be observed in temperatures for recrystallization completion measured using laser ultrasonics and those predicted by the model.

Recrystallization was completed before austenite formation for all initial microstructures as shown in Table 4. The measured austenite volume fraction at any stage of intercritical annealing is essentially independent of the initial microstructure, Fig. 9(b), as was assumed in the model. Thus the model accurately captures the evolution of austenite content before cooling. Further, the kinetics of the subsequent austenite decomposition are predicted accurately using the output of the austenite formation model. Figure 10 shows the microconstituent contents in the final microstructure 
obtained in the experiments and predicted by the model. The predicted final microstructure consists of 12 pct martensite, 18 pct bainite, 12 pct epitaxial ferrite and 58 pct intercritical ferrite. The predictions for martensite and intercritical ferrite are consistent with the experimental observations where $\sim 11$ and $\sim 55$ pct of martensite and intercritical ferrite, respectively, were found to be independent of the initial microstructure. Epitaxial ferrite and bainite contents measured experimentally varied between 18 to 24 pct and 9 to 17 pct, respectively, for different initial microstructures. Considering the accuracy of bainite and epitaxial ferrite volume fraction measurements is $\sim 5$ pct and the transition from austenite-toferrite to bainite formation takes place when austenite volume fraction is between 25 and 35 pct, the modeling and experimental results agree reasonably well.

The performance of the microstructure evolution model has also been evaluated for variations of the industrial thermal path shown in Fig. 9(a) by changing intercritical annealing times by a factor of 0.5 or 2 while maintaining the peak temperature of $780^{\circ} \mathrm{C}$, i.e. the total annealing time are changed from 380 to 190 or $760 \mathrm{~s}$ to replicate annealing of sheets with different thicknesses or line speeds. The ferritebainite-pearlite initial microstructure is employed for these simulations. Upon heating to the intercritical temperature, recrystallization was completed before austenite formation for all annealing times, as shown in Table 5. The maximum

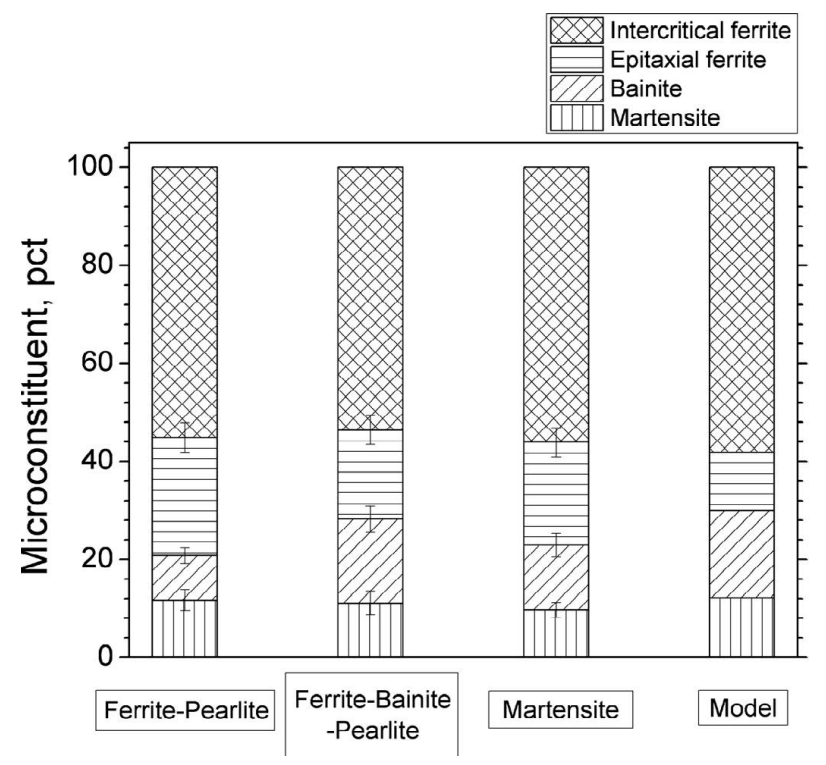

Fig. 10. Comparison of microstructures obtained by laboratory simulation of industrial intercritical annealing process of different initial microstructures and model predictions.

Table 5. Temperatures for recrystallization completion and austenite formation during laboratory simulation of industrial intercritical annealing of different durations for ferritebainite-pearlite initial microstructure.

\begin{tabular}{cccc}
\hline \multirow{2}{*}{$\begin{array}{c}\text { Intercritical } \\
\text { annealing time, s } \mathrm{s}\end{array}$} & $\begin{array}{c}\text { Recrystallization completion } \\
\text { temperature, }{ }^{\circ} \mathrm{C}\end{array}$ & $\begin{array}{c}\text { Austenite formation } \\
\text { temperature }(5 \mathrm{pct}- \\
\text { experiment), }{ }^{\circ} \mathrm{C}\end{array}$ \\
\cline { 2 - 3 } 190 & 731 & 727 & 757 \\
380 & 725 & 712 & 750 \\
760 & 706 & 698 & 751 \\
\hline
\end{tabular}

austenite content reached in the course of intercritical annealing increases from $\sim 41$ to 46 pct as the total annealing time is raised from 190 to $760 \mathrm{~s}$, Fig. 11; the model captures the experimentally observed trends, Fig. 11. The intercritical austenite content agrees within the measurement accuracy with the experimental results for the longer annealing times of 380 and $760 \mathrm{~s}$. For the shorter annealing time of $190 \mathrm{~s}$, the model underestimates the intercritical austenite content somewhat, i.e. 36 pct vs. 42 pct. During the cooling stage, however, the measured and predicted austenite contents agree well such that the model accurately predicts the martensite content in the final microstructure (see Fig. 12). In particularly, the model captures the experimentally observed trend of decreasing martensite content (from 16 to $11 \mathrm{pct}$ ) with increasing annealing time. Predicted volume fractions for the other microconstituents are in agreement with the experimental data for the $760 \mathrm{~s}$ long anneal and the agree-

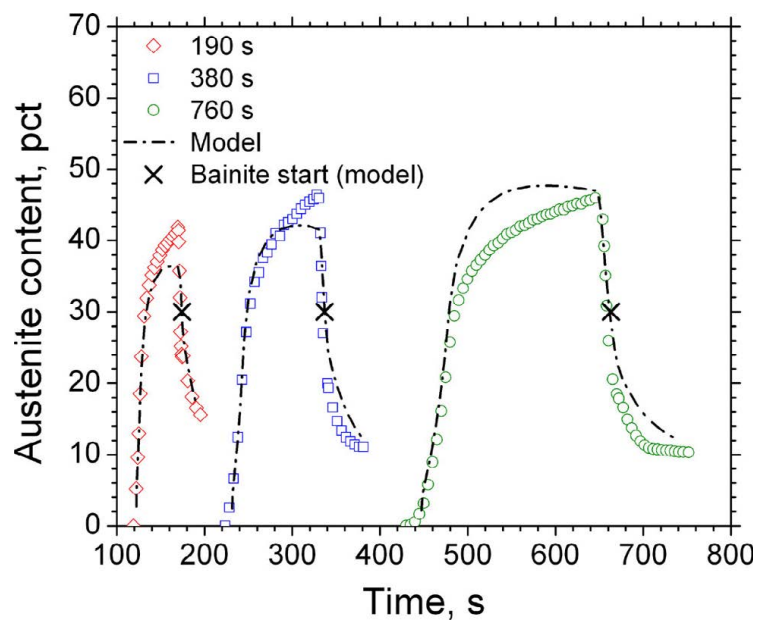

Fig. 11. Effect of annealing time on phase transformations during laboratory simulations of industrial intercritical annealing of ferrite-bainite-pearlite initial microstructure. (Symbols: experiments, lines: model) (Online version in color.)

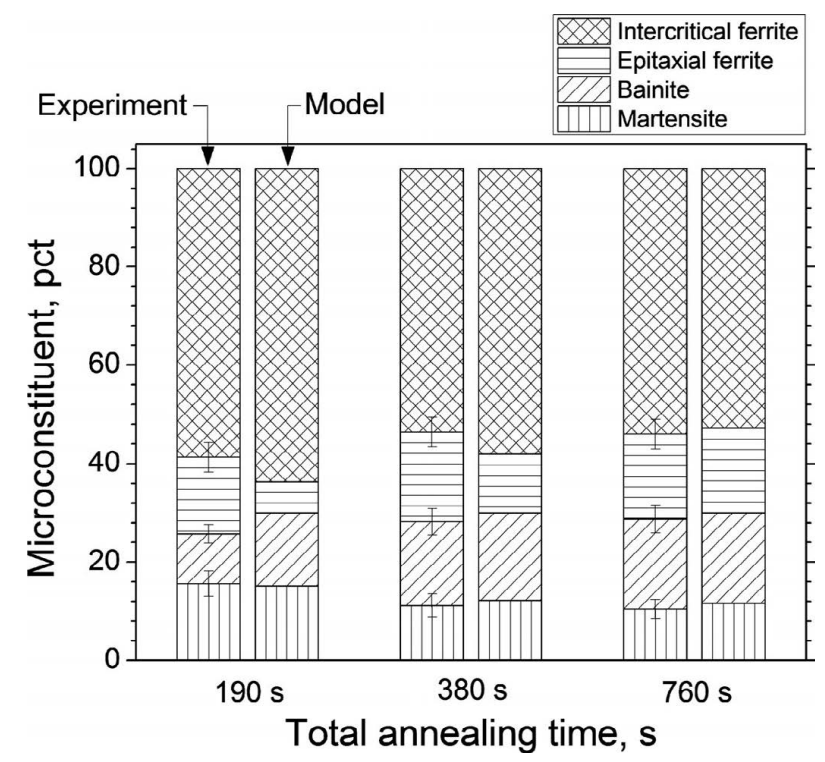

Fig. 12. Comparison of microstructures obtained by laboratory simulations of industrial intercritical annealing of different length for ferrite-bainite-pearlite initial microstructure and model predictions. 
ment is reasonable for the $380 \mathrm{~s}$ anneal as discussed above. There are some more marked deviations for the shorter annealing time of $190 \mathrm{~s}$ that can primarily be attributed to the aforementioned underprediction of the intercritical austenite fraction. As a result the predicted epitaxial ferrite fraction is lower than experimentally observed, albeit the total ferrite fractions agree still reasonably well, i.e. $70 \mathrm{vs}$. 74 pct.

\section{Conclusions}

A microstructure evolution model is proposed for processing of a typical DP600 steel on hot dip galvanizing lines. Based on systematic experimental studies, submodels have been developed for recrystallization, austenite formation and decomposition using the JMAK approach. Recrystallization and austenite formation models have been adopted from a previous study ${ }^{17)}$ and combined with a submodel for austenite decomposition to predict the final microstructure after hot dip galvanizing. The model assumes a coldreduction of $50 \mathrm{pct}$ and incorporates the role of the initial microstructure on recrystallization. Despite a number of simplifications the model has reasonable predictive capabilities as illustrated for a number of laboratory simulated intercritical annealing cycles. In particular, the martensite content that primarily determines mechanical properties of dual-phase steels is accurately predicted with the model.

Even though the present model has been developed for a DP600 steel, bainite is also observed in the microstructure and included in the austenite decomposition model. The accuracy of bainite fraction predictions is not as high as for the martensite content. Moreover, the scale and morphology of the microstructure are not predicted by the model. Directions for refining the model further in predicting these additional microstructure parameters should be evaluated based on a detailed analysis of the structure-property relationships. In terms of the process model development, it is important to connect the microstructure model with a mechanical properties model.

There are numerous additional aspects to extend and refine the model. In its present form, the model is applicable only to the investigated steel chemistry and cold-reduction. An extension to different levels of cold-reduction appears to be rather straightforward and would primarily require extending the recrystallization submodel. The austenite formation and decomposition submodels are independent of the initial microstructure as long as complete recrystallization is attained before the onset of austenite formation. The effect of incomplete recrystallization on austenite formation is not included in the present model but will be of significance for faster annealing routes, e.g. recently constructed continuous annealing lines, and/or for different chemistries, e.g. steels microalloyed with $\mathrm{Nb}$ retarding recrystallization. The proposed modeling approach can be applied to describe the microstructure evolution for other advanced steels, e.g. transformation-induced plasticity or quench-and-partitioning steels, processed through an intercritical annealing step.

\section{Acknowledgements}

The authors would like to acknowledge the financial and in-kind support received from National Research and Engineering Council of Canada (NSERC) and ArcelorMittal Dofasco Inc. (Hamilton, ON, Canada). The microstructure evolution simulator for intercritical annealing, IntAnn, can be downloaded at www.cmpe.ubc.ca/IntAnn.htm.

\section{REFERENCES}

1) M. S. Rashid: Ann. Rev. Mater. Sci., 11 (1981), 245.

2) M. Geib, D. K. Matlock and G. Krauss: Metall. Trans. A, 11 (1980), 1683.

3) R. D. Lawson, D. K. Matlock and G. Krauss: Metallography, 13 (1980), 71.

4) S. Zaefferer, J. Ohlert and W. Bleck: Acta Mater., 52 (2004), 2765.

5) M. J. Santofimia, L. Zhao and J. Sietsma: Metall. Mater. Trans. A, 40 (2009), 46.

6) M. J. Santofimia, C. Kwakernaak, W. G. Sloof, L. Zhao and J. Sietsma: Mater. Charact., 61 (2010), 937.

7) H. Chen, E. Gamsjäger, S. Schider, H. Khanbareh and S. van der Zwaag: Acta Mater., 61 (2013), 2414.

8) K. Zhua, H. Chen, J.-P. Masse, O. Bouaziz and G. Gachet: Acta Mater., 61 (2013), 6025.

9) V. Colla, M. DeSanctis, A. Dimatteo, G. Lovicu and R. Valentini: Metall. Mater. Trans. A, 42 (2011), 2781.

10) R. Mohanty, O. Girina and N. Fonstein: Metall. Mater. Trans. A, 42 (2011), 3680.

11) C. Bos, M. G. Mecozzi and J. Sietsma: Comput. Mater. Sci., 48 (2010), 692.

12) M. Militzer: Curr. Opin. Solid St. M, 15 (2011), 115.

13) J. Rudnizki, U. Prahl and W. Bleck: Integr. Mater. Manuf. Innov., 1 (2012), 1.

14) K. Mukunthan and E. Hawbolt: Metall. Mater. Trans. A, 27 (1996), 3410 .

15) H. S. Zurob, C. R. Hutchinson, Y. J. M. Bréchet and G. Purdy: Acta Mater., 50 (2002), 3077.

16) J. Huang, W. J. Poole and M. Militzer: Metall. Mater. Trans. A, 35 (2004), 3363.

17) M. Kulakov, W. J. Poole and M. Militzer: Metall. Mater. Trans. A, 44 (2013), 3564

18) R. R. Judd and H. W. Paxton: Trans. Metall. Soc. AIME, 242 (1968), 206.

19) P. A. Wycliffe, G. R. Purdy and J. D. Embury: Can. Metall. Q., 20 (1981), 339.

20) S. K. Nath, S. Ray, V. N. S. Mathur and M. L. Kapoor: ISIJ Int., 34 (1994), 191.

21) P. C. Campbell, E. B. Hawbolt and J. K. Brimacombe: Metall. Mater. Trans. A, 22 (1991), 2779.

22) S. J. Jones and H. K. D. H. Bhadeshia: Acta Mater., 45 (1997), 2911.

23) M. Militzer, E. B. Hawbolt and T. R. Meadowcroft: Metall. Mater. Trans. A, 31 (2000), 1247.

24) H. Matsuda and H. K. D. H. Bhadeshia: P. Roy. Soc. Lond. A Mat., 460 (2004), 1707.

25) S. Sarkar and M. Militzer: Mater. Sci. Technol., 25 (2009), 1134.

26) M. De Meyer, J. Mahieu and B. C. De Cooman: Mater. Sci. Technol., 18 (2002), 1121.

27) T. Iung, M. Azuma, O. Bouaziz, M. Gouné, A. Perlade and D. Quidort: Mater. Sci. Forum, 426-432 (2003), 3849.

28) T. Senuma: ISIJ Int., 52 (2012), 679.

29) E. E. Underwood: Quantitative Stereology, Addison-Wesley, Reading, (1970).

30) M. Militzer, T. Garcin, M. Kulakov and W. J. Poole: Proc. of 5th Baosteel Biennial Academic Conf., Baosteel Group Corporation, Shanghai, (2013), CD-ROM.

31) D. Artymowicz, B. Hutchinson and M. Nogues: Mater. Sci. Tech. Ser., 18 (2002), 1142.

32) H. Chen and S. van der Zwaag: Comput. Mater. Sci., 19 (2010), 801.

33) H. Chen, B. Appolaire and S. van der Zwaag: Acta Mater., 59 (2011), 6751.

34) E. A. Brandes and G. B. Brook: Smithells Metals Reference Book, Elsevier, New York, (1998).

35) M. Avrami: J. Chem. Phys., 7 (1939), 1103.

36) W. A. Johnson and R. F. Mehl: Trans. Am. Inst. Min. Metall. Pet. Eng., 135 (1939), 416.

37) A. Kolmogorov: Izv. Acad. Sci. USSR, Math. Ser., 1 (1937), 355.

38) J. W. Cahn: Acta Metall., 4 (1956), 572.

39) M. Lusk and H.-J. Jou: Metall. Mater. Trans. A, 28 (1997), 287. 